\title{
Effects of combined oral contraceptive pills on thyroid function tests in Mosul City
}

\author{
Wahda B. Al-Youzbaki *; Mohammed Daood Mahmood ** \\ Departments. of Pharmacology, *Mosul College of Medicine, ** College of Pharmacy, University of Mosul, \\ Iraq \\ Received Accepted \\ $1 \leq .11 .1 \cdot 1 \cdot$
}

\begin{abstract}
Background: There are very little studies to determine the effects of combined oral contraceptive pills (COCPs) on thyroid function tests in hormonal contraceptive users at least in our locality.

Objective: To evaluate the effects of COCPs on serum level of thyroid stimulating hormone $(\mathrm{TSH})$, free triiodothyronine $\left(\mathrm{FT}^{\mathrm{r}}\right)$ and free tetraiodothyronine (thyroxine) $\left(\mathrm{FT}^{\varepsilon}\right)$ and in relation to the duration of their usage in Mosul City.

Design: A case control study.

Subject \& Methods: This study was conducted during the period from September $r \ldots \wedge$ to March $r \ldots q$. A total of $\vee \wedge$ healthy married women, age range between 19_ro years, from those who were attending AL-Batool and AL-Khansa Family Planning Centers in Mosul, who were taking Microgynon tablets which are one of monophasic, second generation combined oral contraceptive pills (COCPs) (contain $\because \cdot r \mathrm{mg}$ of ethinyl estradiol and $\cdot .10 \mathrm{mg}$ levonorgestrel) $(\mathrm{N}=\varepsilon \wedge)$ for a period ranged between $r$ months to $\bullet$ years and these were considered the users group. Other $\varepsilon \cdot$ healthy married women who did not use any hormonal contraceptives and were drawn from the same population and matched for age, body mass index (BMI) with the users group and they were considered as the non users groups. Blood samples $\left({ }^{\circ} \mathrm{ml}\right)$ were obtained from COCPs users and non-user groups. The sera obtained from the blood samples were used for the estimation of serum TSH, FTr ${ }^{2}, \mathrm{FT}^{\leqslant}$using Menividus analytic device.

Results: This study revealed non significant differences in TSH, FT ${ }^{r}$ and FT $\varepsilon$ serum levels between COCPs users and non users and no correlation between serum TSH, $\mathrm{FT}^{\top}$ and $\mathrm{FT}^{\leqslant}$levels and duration of hormonal contraceptives usage.
\end{abstract}

Conclusion: This study supported that the free thyroid hormone tests are the tests of choice in assessing thyroid function of women taking COCPs and concluded that COCPs can be regarded as a safe drugs in women using these types of hormonal as far as thyroid function is concerned.

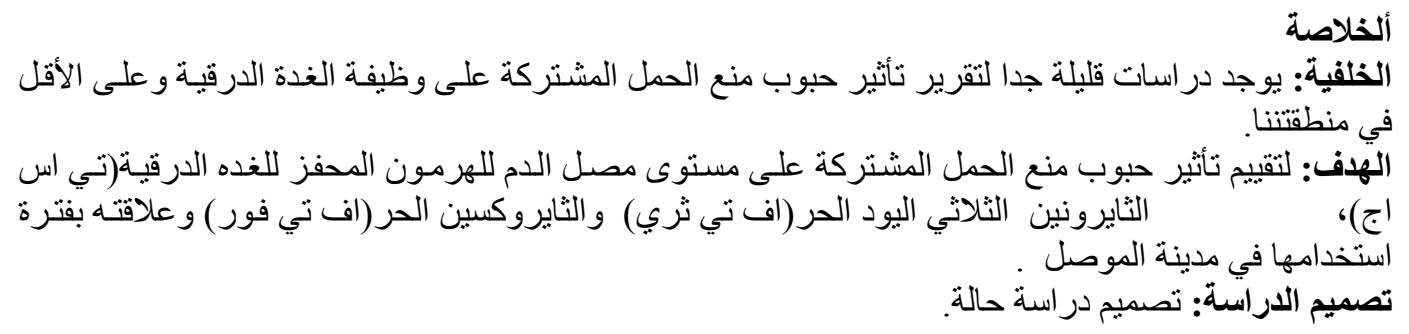




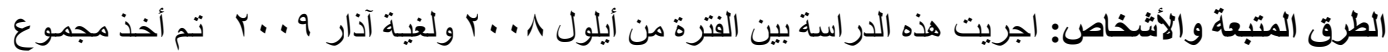

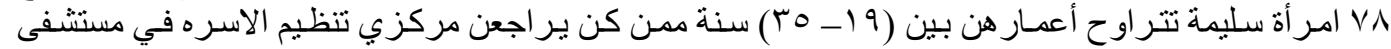

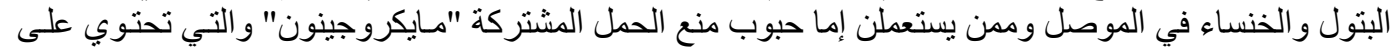

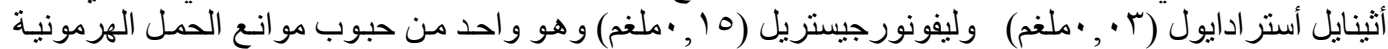

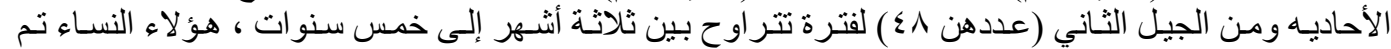

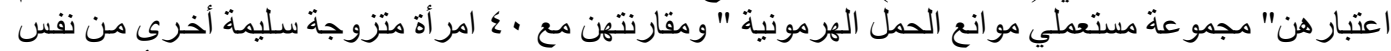

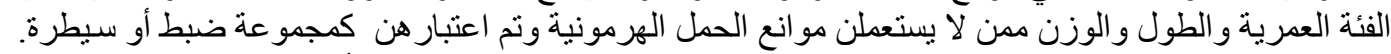

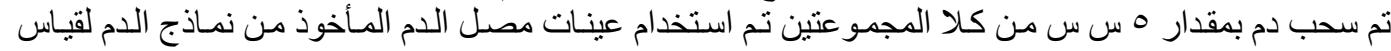

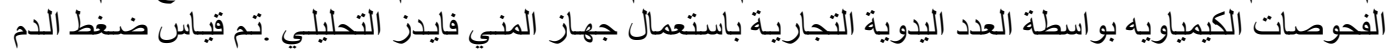

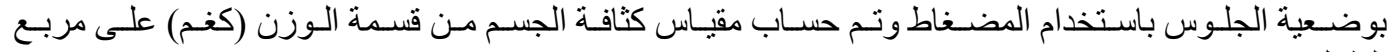

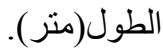

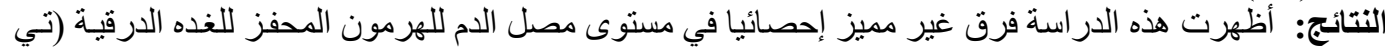

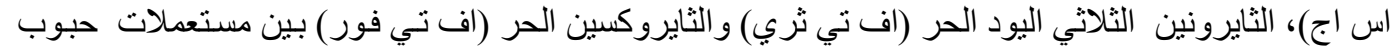

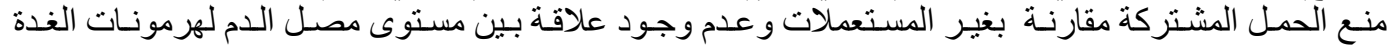

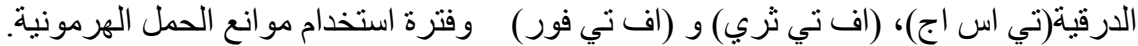

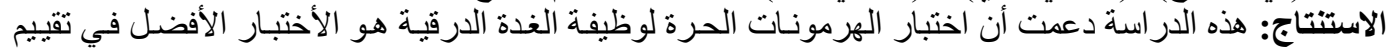

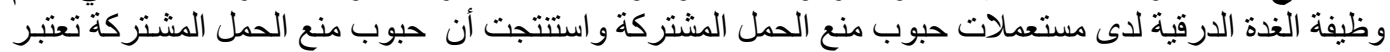

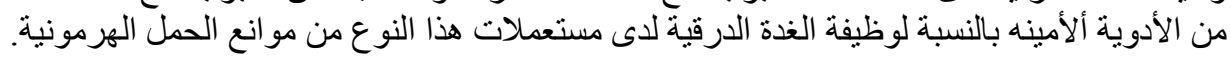

I $\mathrm{t}$ has been reported that estrogen increase serum thyroxin-binding globulin (TBG) concentration because this hormone may enhances hepatic production of $\mathrm{TBG}^{\prime}$ and decrease TBG clearance ',r, thus increasing serum total tetraiodothyronine (thyroxine) $\left(\mathrm{TT}_{\varepsilon}\right)$ and to a lesser extent total triiodothyronine $\left(\mathrm{TT}_{r}\right)^{\prime}{ }^{\prime}{ }^{r}$. As a result, increased $\mathrm{TT}_{\varepsilon}$ and $\mathrm{TT}_{r}$ are seen in states of excessive estrogen and/or progestin, such as pregnancy, hormonal replacement therapy (HRT) and oral contraceptives usage ${ }^{\varepsilon, 0}$. This phenomenon may cause problems in clinical diagnoses when $\mathrm{TT}_{\varepsilon}$ or $\mathrm{TT}_{r}$ is used for these patients.

Oral contraceptives (birth control pills) are medicines taken by mouth to help in preventing pregnancy, contain artificially made form of two hormones naturally produced in the body (estrogen and progesterone) so called COCPs ". They are the most effective, safe, reliable and popular form of reversible contraception ${ }^{\vee}$.

The results of a study done by Duijkers et al. ${ }^{\wedge}$ on healthy women aged $\backslash \Lambda_{-} \leqslant \cdot$ years used either vaginal ring delivering $\because \cdot 10 \mathrm{mg}$ ethinyl estradiol and $\cdot .1 r \mathrm{mg}$ of etonogestrel per day, or COCPs containing $\cdot \cdot r$ $\mathrm{mg}$ ethinyl estradiol and $.10 \mathrm{mg}$ levonorgestril for six cycles, found that both the vaginal ring and the oral contraceptive have no clinically relevant effects on carbohydrate metabolism, adrenal or thyroid function tests.

Other study ${ }^{9}$ about the effects of sex-steroid administration on the pituitary-thyroid axis in trans sexuals, concluded that estrogens do not affect $\mathrm{T}^{\mathrm{r}} / \mathrm{T} \varepsilon$ ratio, irrespective of the route of administration. Whereas Shifren et al. ' suggested that in comparison with COCPs, transdermal route exerted minimal effects on the total and free concentrations of $T^{\varepsilon}, T^{r}$ and their binding proteins. In contrast to what would be expected theoretically the study done by Grüning et al ., found that $\mathrm{FT}^{r}$ values decreased significantly during COCPs usage while TSH and TT $\varepsilon$ were unaffected.

In a recent cohort study done by Sänger et al. ${ }^{r}$ in $\triangle 9$ women ingested 
this monophasic COCPs for it cycles, the serum concentrations of TBG were elevated by about $70 \%$, likewise, an increase in $\mathrm{TT}^{\mathrm{r}}$ and $\mathrm{TT}^{\varepsilon}$

The aim of this study is to assess the effect of COCPs Microgynon $(\because \sim \mathrm{mg}$ Ethinylestradiol (EE) and $\cdot 10 . \mathrm{mg}$ Levonorgestrel (LNG)) on thyroid function tests (TSH, FT $\varepsilon$ and $\mathrm{FT}^{ }$), and in relation to the duration of use by these hormonal contraceptive users in comparison to non users aged matched women as control.

\section{Subjects and Methods}

The study was conducted in the largest two centers of Family Planning in Mosul city: Al-Batool Family Planning Center and AlKhansa Family Planning Center, from September $r \cdots \wedge$ to March $r . .9$. This study included $\leqslant \wedge$ apparently healthy women who were attending Al-Batool Family Planning Center and Al-Khansa Family Planning Center and having the following inclusion criteria: Age range between 19-ro years old and their body mass index $(\mathrm{BMI})<$ ro. All married but not pregnant, nor lactating but were fertile at the time of study and having regular menstrual cycle. Apparently healthy, were not use any other medications at the time of study. Neither smoker nor alcoholic. These women were taking combined oral contraceptive pills (COCPs), called Microgynon (Schering, Germany). Each tablet contains $\because r \mathrm{mg}$ Ethinylestradiol (EE) and $\cdot .10 \cdot \mathrm{mg}$ Levonorgestrel (LNG) for more than $r$ months.

The non-users group included \&. women, from those, attending Al-Batool Family Planning Center, women works at Colleges of Medicine and Pharmacy, by $r \cdot-\varepsilon \cdot \%$, but non significant changes in free $\mathrm{T}^{\varepsilon}$ were found.

University of Mosul, who had the same criteria as the users group except that they were not using any hormonal contraceptives, instead they used either a barrier method or mechanical methods and they were volunteered for comparison.

Five $\mathrm{ml}$ of venous blood were withdrawn, using a disposable syringe from the contraceptive users and non-users. The blood was allowed to clot in a plain tube at room temperature and then the serum was separated by centrifugation at $r \cdots$ rpm for 1 . minutes and then kept frozen at $r \cdot{ }^{\circ} \mathrm{C}$ to be analyzed thereafter. Serum TSH, FT $\varepsilon$ and FT ${ }^{r}$ were measured, using the ELFA technique (enzyme linked fluorescent assay), and TSH, FT $\varepsilon$ and FT ${ }^{r}$ kits ( Ref. $r$. $\quad \varepsilon \cdot$, $r \cdot \varepsilon \cdot 1$ and $r \cdot \varepsilon \cdot r$ respectively ) from biomerieux, France were used.

Standard statistical methods were used to determine the mean and standard deviation (SD). Unpaired student t-test was used to compare the results for measured biochemical parameters between hormonal contraceptive users and non-users.

Linear regression analysis [Pearson correlation coefficient (r)] was performed for finding the degree of association between different parameters. ANOVA Test (Analysis of Variance) was used to identify the variation in the different variables in relation to the duration of hormonal contraceptive user groups. $P<\because .0$ was 
considered to be statistically significant.

The approval of the study protocol by an ethic committee has Health and College of Medicine, University of Mosul, Iraq.

\section{Results}

A total number of $\leqslant \wedge$ women who used COCPs were included in this study, with mean age $\pm \mathrm{SD}$ of $r \cdot . \tau_{ \pm} \pm$r. $\left.\varepsilon \cdot\right)$, those have been considered to represent the exposed (COCPs users) group. Another \& . women with mean age \pm SD of been obtained from the Local Health Committee, Ministry of

r9. $0 \pm\{.0 \cdot$ years, who did not use or used non hormonal contraceptives such as condom or IUCDs and were considered to represent the non exposed group (non-users) group.

No significant differences between the mean serum TSH, FT ${ }^{r}$ and FT $\varepsilon$ levels in the COCPs users compared with the non users (Table 1)

Table ': Comparison between mean serum levels of measured thyroid hormones of COCPs users and non-user groups

\begin{tabular}{|c|c|c|c|}
\hline \multirow[b]{2}{*}{ Parameters } & \multicolumn{2}{|c|}{ Mean \pm SD } & \multirow[b]{2}{*}{ P-Value } \\
\hline & $\begin{array}{c}\text { COCPs Users } \\
(n=\varepsilon \wedge)\end{array}$ & $\begin{array}{c}\text { Non-Users } \\
(n=\varepsilon \cdot)\end{array}$ & \\
\hline $\mathrm{FT}^{\mu}(\mathrm{Pmol} / \mathrm{L})$ & $\varepsilon . v \leqslant \pm \cdot .9$. & $\{.7 \wedge \pm \cdot . \wedge)$ & NS \\
\hline FT $\varepsilon(\mathrm{Pmol} / \mathrm{L})$ & $11.7 \leq \pm 1.0 r$ & $11 . \wedge r_{ \pm 1} . v_{0}$ & NS \\
\hline TSH (Pmol/L) & $1 . v \leqslant \pm \cdot .9 \leqslant$ & $1 . V I \pm \cdot . \wedge r$ & NS \\
\hline
\end{tabular}

No significant differences in the mean serum TSH, $\mathrm{FT}^{\top}$ and $\mathrm{FT}^{\varsigma}$ levels among COCPs users group according to duration of use has been demonstrated in Table $r$. 
Table $r$ : comparison between mean serum levels of measured thyroid hormones among COCPs users group according to duration of use

\begin{tabular}{|c|c|c|c|c|c|}
\hline \multirow[b]{2}{*}{ Parameters } & \multicolumn{3}{|c|}{$($ Mean \pm SD $)(n=\varepsilon \wedge)$} & \multirow[b]{2}{*}{ F-value } & \multirow[b]{2}{*}{ P-value } \\
\hline & $\begin{array}{l}\text { COCPs } \\
\text { Users } \\
\leq ' y r \\
(n=l v)\end{array}$ & $\begin{array}{l}\text { COCPs } \\
\text { Users } \\
1<\mathrm{yr}<0_{\mathrm{yr}} \\
\left(\mathrm{n}=\mathrm{r}^{\circ}\right)\end{array}$ & $\begin{array}{l}\text { COCPs } \\
\text { Users } \\
\geq 0_{y r} \\
(n=7)\end{array}$ & & \\
\hline $\mathrm{FT}^{\mathrm{r}}(\mathrm{Pmol} / \mathrm{L})$ & $\varepsilon .7 V_{ \pm} \cdot .09$ & $\varepsilon . V \Gamma_{ \pm} \cdot .9 \vee$ & $\varepsilon . \vee \cdot \pm \cdot . \varepsilon \cdot$ & $\because \leqslant 9$ & NS \\
\hline $\mathrm{FT} \varepsilon(\mathrm{Pmol} / \mathrm{L})$ & $11.0 r_{ \pm 1} .00$ & $11.79 \pm 1.0 r$ & $11.7 \cdot \pm 1 . \mathrm{VA}$ & $\because 9 r$ & NS \\
\hline TSH(Pmol/L) & $1.7 V_{ \pm} \cdot .9$ & $1 . \vee q_{ \pm} \cdot . \wedge r$ & $1 . V Y_{ \pm} \cdot .0 V$ &. $.1 \wedge r$ & NS \\
\hline
\end{tabular}

\section{Discussion}

The hormonal contraceptive used in this study was "Microgynon" tablets, which is one of the monophasic, second generation COCPs $(\cdot \cdot r \mathrm{mg}$ ethinly estradiol and $\because 10 \mathrm{mg}$ levonorgestrel), because COCPs are the most commonly used method of contraception in Iraq, as it was found that oral pills represent the most popular, about $r \div \%$ of current users use oral pills ${ }^{\prime r}$. Also, in another study done in Mosul City', found that the most common type of contraceptive methods used was the oral pills, (\& . . \% ) (including COCPs in $r$ r. $\%$ and progesterone only pills (POPs) in $1 \cdot . r \%$ ) of the users '.

Since the introduction of hormonal contraceptives in the early $197 . \mathrm{s}$, repeated attention has been focused on possible beneficial and harmful side effects ${ }^{10}$. Among the possible impact, the relation between hormonal contraceptive use and thyroid function tests has been studied but the results of these studies, however, have been equivocal. This study found that there were no significant changes in the mean serum levels of TSH, FT ${ }^{r}$ and $\mathrm{FT} \varepsilon$ among COCPs users in comparison to the non-users, which is in agreement with many studies A, 'r, ' differences in thyroid parameters in women taking COCPs containing ethinly estradiol and levonorgestrel in comparison to the control. In a recent cohort study done by Sänger et al., "r in 09 women ingested this monophasic COCPs for it cycles, the serum concentrations of TBG were elevated by about $10 \%$, likewise, an increase in TTr and $\mathrm{TT} \leqslant$ by $r \cdot-\varepsilon \cdot \%$, but non significant changes in free $T \varepsilon$ were found.

Other two studies ${ }^{1 v, i s}$ in agreement with our results and 
concerning thyroid reference levels, concluded that the use of oral contraceptives was a significant predictor for variation in $\mathrm{TT}^{\varepsilon}$ and $\mathrm{TT}^{\mathrm{r}}$ concentrations due to estrogenevaluation of thyroid diseases owing to their capacity to modulate the limits of thyroid hormone distinct reference intervals.

The present study showed no correlation between serum TSH, FT $^{\top}$ and FT $\varepsilon$ levels and duration of hormonal contraceptive usage which indicates that the effects of contraceptives on thyroid tests is time independent. In line with this, Sänger et al.,' ${ }^{\top}$ observed that during hormonal contraceptive usage, a steady state in the effects on thyroid hormones and androgen parameters was reached within $r$ months and that the changes in the various hormonal parameters did not substantially differ between conventional and extended-cycle regimen.

In the present study, the free hormones (FTr \& $\mathrm{FT}^{\varepsilon}$ ) were evaluated instead of the routinely measured total forms (TTr \& $\mathrm{TT}^{\boldsymbol{\varepsilon}}$ ) in Iraq, since total test is a measure of bound and free hormone, and the change in the level of thyroid hormone binding protein, as in subjects using oral contraceptives, produce corresponding changes in the total $T^{\varepsilon}$, even though levels of physiologically active free $T \leqslant$ are unchanged ${ }^{1,0,19}$; thus a patient may be physiologically normal but has an abnormal total serum hormonal level. So, FTr and FT $\varepsilon$ in the serum can be measured directly, avoiding the hazard of interpreting total levels ${ }^{r \cdot, r}$. Furthermore, because the free rather than bound thyroid hormone is subjected to homeostatic control by the hypothalamicpituitary-thyroid axis ${ }^{r}$, estimation of free thyroid hormone mediated TBG-induced hepatic synthesis, where as $\mathrm{FT}^{\varepsilon}$ and $\mathrm{FT}^{\mathrm{r}}$ were insignificantly affected and that the use of contraceptives should be considered in diagnostic concentrations are theoretically preferable to $\mathrm{TT}^{\varsigma}$ and $\mathrm{TT}^{\mathrm{r}}$ tests, indicating that free serum thyroxin is the test of choice in assessing the functional thyroid status of women taking oral COCPs or HRT ${ }^{r, r}$.

In conclusion, COCPs can be regarded as a safe drugs in women using these hormonal contraceptives as far as thyroid function is concerned and the use of free thyroid hormone tests should be followed instead of measuring the total thyroid hormone in assessing thyroid function of women taking hormonal contraceptives.

\section{References}

1- Sandy HJ, Cheng WC, Jang MW, Tsai KS. Effects of long-term use of raloxifene, a selective estrogen receptor modulator, on thyroid function test profiles. Am Assocat

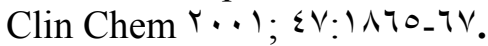

r. Bartalena L, Bogazzi F, Brogioni S, Burelli A, Scarcello G, Martino E. Measurement of serum free thyroid hormone concentrations: An essential tool for the diagnosis of thyroid dysfunction. Horm Res 1997; ₹0(T-0): $1 \leqslant Y-Y$.

r- Muller AF, Verhoeff A, Mantel MJ, De Jong FH, Berghout A. Decrease of free thyroxine levels after controlled ovarian hyperstimulation. J Clin Endocrinol Metab Y...; $10: 0 \leqslant 0.0 \leqslant 1$.

¿- Swanson MA, Custer TR, Suey CM. Free thyroxine and free thyroxine index in women taking oral contraceptives. Clin Nucl Med 19ᄉ1; $7(\varepsilon):|7 \Lambda-V|$.

- Nelson JC, Yoo EW, Wilcox RB. Accuracy issues in free thyroxine 
testing methods Semin Perinatol r... $; r r(\tau): \varepsilon \cdot r_{-} \tau$.

7. Ross-Flanigan N. Oral contraceptives. Gale encyclopedia of medicine, Gale group 1999. From www. find articles.com.

V. Burkman RT, Collins JA, Shulman LP, Kell Williams J. Current perspectives on oral contraceptives. Am J Obstet Gynecol $Y .$. । ; 1 $10: \varepsilon-$ ir.

^- Duijkers I, Killick S, Bigrigg A, Dieben TO. A comparative study on the effects of a contraceptive vaginal ring Nuva Ring and an oral contraceptive on carbohydrate metabolism and adrenal and thyroid function. Eur J Contracept Reprod Health Care $\left.\left.r . . \varepsilon ; q^{q}(r): 1\right)^{\top}\right) \_\varepsilon$.

9- Bisschop PH, Toorians AW, Endert $E$, et al. The effects of sex-steroid administration on the pituitarythyroid axis in transsexuals. Eur $\mathbf{J}$ Endocrinol $Y \ldots \%$; $100(1): 11-7$.

1.-Shifren JL, Desindes S, McIlwain $\mathrm{M}$, Doros G, . A randomized, openlabel, crossover study comparing the effects of oral versus transdermal estrogen therapy on serum androgens, thyroid hormones, and adrenal hormones in naturally menopausal women. Menopause $\left.r \cdot . \cdot v_{;}\right) \leqslant(7): 910_{-} 9 \leqslant$.

1)-Grüning T, Zöphel K, Wunderlich $\mathrm{G}$, Franke WG. Influence of female sex hormones on thyroid parameters determined in a thyroid screening.

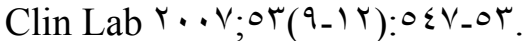

I r-Sanger N, Stahlberg S, Manthey T et al. Effects of an oral contraceptive containing $r \cdot \mathrm{mcg}$ ethinyl estradiol and $r \mathrm{mg}$ dienogest on thyroid hormones and androgen parameters: Conventional VS. extended-cycle use. Contracept r... $; V^{\prime}(\tau):\{r \cdot-0$.

$1 \%$-Khalil IM, Prevalence of different contraceptive methods among Iraqi women. Thesis of Arabic Board in Obstetrics and Gynecology 1999.
Iక-Al-Youzbaki WB. Contraceptive Practices in Mosul. Iraqi $\mathrm{J}$ Comm

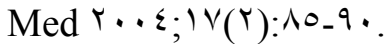

10-Beral V. Mortality among oral contraceptive users. Royal Collage of General Practitioner's Oral Contraception Study. Lancet

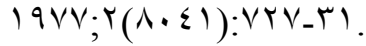

17 -Wiegratz I, Kutschera E, Lee JH et al. Effect of four different oral contraceptives on various sex hormones and serum-binding globulins. Contracept r..r;Tr( (1): ro-rr.

IV-Toldy E, Locsei Z, Rigo E, Kneffel $\mathrm{P}$, et al. Comparative analytical evaluation of thyroid hormone levels in pregnancy and in women taking oral contraceptives: A study from an iodine deficient area. Gynecol Endocrinol

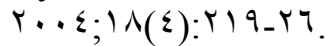

\^-Kratzsch J, Fiedler GM, Leichtle A et al. New reference intervals for thyrotropin and thyroid hormones: based on National Academy of Clinical Biochemistry. Am Associat Clin Chem Y..0 0 01:1 $\{1 \cdot-7$.

19-Bhatkar SV, Rajan MG, Velumani A, Samuel AM. Thyroid hormone binding protein abnormalities in patients referred for thyroid disorders. Indian $\mathrm{J}$ Med Res Y.. $\{; 1\} \cdot(r): 1 \% \cdot .0$.

$r \cdot-$ John EM. Direct and indirect free thyroxine assay methods: Theory and Practice. Clin Chem r... ; $\leqslant \vee$ : Iror_tr.

Y - -Sapin R, Schlienger JL. Thyroxine $\left(\mathrm{T}^{\varepsilon}\right)$ and tri-iodothyronine $\left(\mathrm{T}^{\mathrm{r}}\right)$ determinations: Techniques and value in

the assessment of thyroid function. Ann Biol Clin r..r; $r(\varepsilon): \varepsilon \backslash 1-r \cdot$

rr-Schussler GC. The thyroxinebinding proteins. Thyroid r. $\cdot ; \cdot(r): \mid \leq 1-9$.

$r$ r-Fadhel NN. Knowledge, Altitude and Practice of Contraceptive Methods among Iraqi Women. MSc 
Thesis in Community Medicine, Mosul r..r. College of Medicine, University of 